\title{
Prevalence and socioeconomic determinants of dental sealant use among schoolchildren in Saudi Arabia
}

\author{
D.E. Al Agili, ${ }^{1}$ H.A. Niazy² and M.A. Pass ${ }^{3}$
}

$$
\begin{aligned}
& \text { معدل انتشار استخدام الختّاّمات السنبّة وححدّداتها الاجتماعية لدى أطفال المدارس في المملكة العربية السعودية }
\end{aligned}
$$

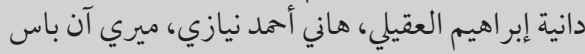

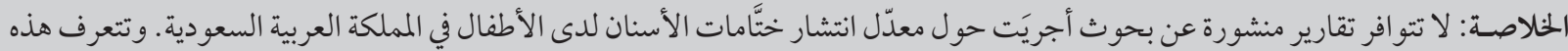

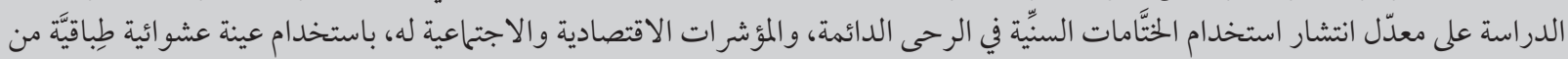

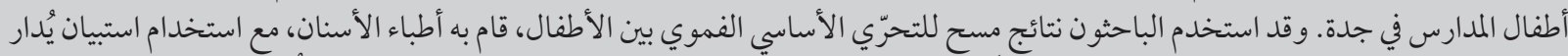

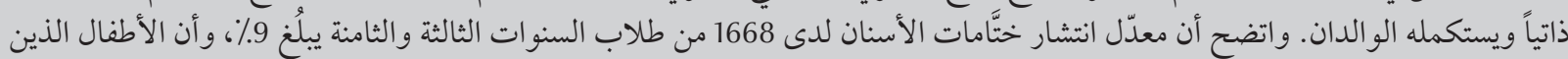

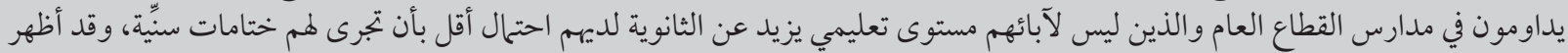

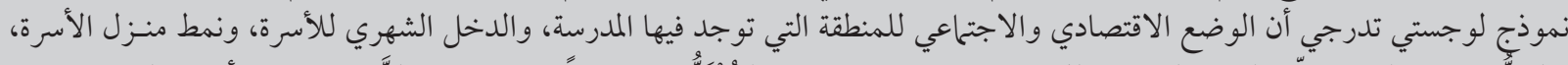

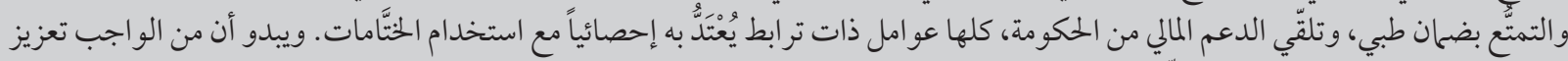

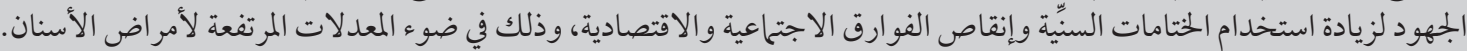

ABSTRACT There are no published research reports on the prevalence of dental sealant use in children in Saudi Arabia. This study determined the prevalence and socioeconomic indicators of dental sealant use on the permanent molars of a stratified random sample of schoolchildren in Jeddah. A basic oral screening survey of students was conducted by dentists and a self-administered questionnaire was completed by parents. The prevalence of dental sealant use among 1668 3rd and 8th grade students was 9.0\%. Students who attended public schools and those who had fathers with lower than high-school education were less likely to have sealants. A stepwise logistic regression model showed that socioeconomic status of school district, family's monthly income, family's type of home, having medical insurance and receiving government financial support were significantly associated with sealant use. Efforts to increase sealant use and to reduce socioeconomic disparities appear warranted in the light of high rates of dental disease.

Prévalence et déterminants socioéconomiques de l'utilisation de la résine de scellement chez des élèves en Arabie saoudite

RÉSUMÉ Aucun rapport de recherche n'a été publié sur la prévalence de l'utilisation de la résine de scellement chez les enfants en Arabie saoudite. L'étude a déterminé la prévalence et les indicateurs socioéconomiques de l'utilisation de la résine de scellement sur les molaires permanentes d'un échantillon randomisé et stratifié d'élèves à Djeddah. Une enquête de dépistage de base de la santé bucco-dentaire des élèves a été menée par des dentistes et un auto-questionnaire a été rempli par les parents. La prévalence de l'utilisation de la résine de scellement chez 1668 élèves de 3e et de $8^{e}$ années à l'école était de 9,0\%. Les élèves des établissements publics et ceux dont les pères n'étaient pas allés au lycée étaient moins susceptibles de porter des résines de scellement. Un modèle logistique par étapes a révélé que le statut socioéconomique du district de l'école, le revenu mensuel et le type de logement de la famille, le fait d'avoir une assurance médicale et de bénéficier d'une aide financière du gouvernement étaient des facteurs fortement associés à l'utilisation de la résine de scellement. Des efforts pour augmenter l'utilisation de la résine de scellement et pour réduire les disparités socioéconomiques semblent justifiés à la lumière des taux élevés des maladies dentaires.

'Department of Preventive Dental Sciences; ${ }^{2}$ Department of Oral and Maxillofacial Surgery, Faculty of Dentistry, King Abdulaziz University, Jeddah, Saudi Arabia (Correspondence to D.E. Al Agili: dalagili@kau.edu.sa).

${ }^{3}$ Department of Health Care Organization and Policy, University of Alabama at Birmingham, Birmingham, Alabama, United States of America. Received: 22/11/10; accepted: 12/12/11 


\section{Introduction}

Dental caries is the most common preventable chronic disease of childhood [1]. The prevalence of dental caries in children has declined in many developed countries yet remains high in most developing countries [2]. In Saudi Arabia, less than $10 \%$ of children are caries-free [3-8]. The decayed, missing and filled permanent teeth (DMFT) index values among 12-year-old children range from $3-5$, indicating moderate to severe oral disease [8-10]. These values are still very far from the World Health Organization (WHO) 2000 global goals for oral health of no more than 3 DMFT in 12-year-old children and at least $50 \%$ of 6 -year-olds caries-free [2].

Although fluoride use has been credited with much of the decline in dental caries worldwide throughout the past decades, it has limited effectiveness on the chewing surfaces (pits and fissures) of teeth [11]. Most of the untreated dental caries is found in the pits and fissures of molar teeth which represent only $12.5 \%$ of tooth surfaces $[6,12]$. Pit and fissure sealants are primary preventive measures for dental caries affecting molar teeth $[13,14]$. Scientific evidence shows that sealants are highly effective in preventing dental caries $[15,16]$. Reductions in dental caries range from $87 \%$ at 12 months to $60 \%$ at 48-54 months post-application [15].

Dental sealant use in children and adolescents varies worldwide. It is very high ( $50 \%$ or more) in northern European countries where comprehensive oral health care systems are available and services are offered free of charge to both children and adolescents [17-19]. In Greek children, only 8\% of 12- and 15-year-olds had at least 1 sealed permanent molar. The educational level of parents and residence in urban areas were statistically significantly associated with a higher percentage of sealant use [20]. This can be compared with the United States (US), where $29 \%$ of 6-11-yearolds and $37 \%$ of $12-15$-year-olds had at least 1 sealed permanent tooth [21]. Moreover, dental sealant use is lower in non-white and low-income American children [21]. These rates are still well below the US Healthy People 2010 objective of $50 \%$ [22].

There are no published research reports on the prevalence of sealant use in children in Saudi Arabia, and strong, publicly supported dental sealant programmes are lacking. The aims of this study were to determine the prevalence of pit and fissure sealant use in the permanent molars of children and adolescents in Jeddah, Saudi Arabia, and to determine the socioeconomic indicators of sealant use. This research will help identify and target communities in need of dental public health prevention programmes.

\section{Methods}

\section{Study design and sampling method}

The study design was cross-sectional. A stratified random sample of schools was selected. School selection was stratified by grade ( $3 r d$ or 8 th), type (public or private), and region (geographical location in the city) using the Jeddah city schools' list. The number of schools in each region of Jeddah was verified and the schools were selected according to their actual proportions in the city. All 3rd and 8th male and female grade students in these schools were included.

\section{Sample size}

In 2008, there were 621 elementary and 400 middle schools, yielding a total of 389513 rd and 39389 8th graders respectively. The schools in Saudi Arabia are segregated by sex. Using a 2:1 elementary to middle school ratio, 8 elementary schools from each sex (total 16) and 4 middle schools from each sex (total 8) were included in the study. Using the sample size calculator with a $95 \%$ confidence level and a confidence interval of 5 , the minimum recommended sample size was 380 3rd and 380 8th graders from each boys' and girls' school system. The sample was increased to 1600 (800 female and 800 male) students to account for nonresponders. The final sample consisted of 1668 male and female students.

\section{Procedure}

The protocol of this study was approved by the ethics committee of the Deanship of Scientific Research in King Abdulaziz University, Jeddah, Saudi Arabia. Approval was also obtained from the director of the Department of Education prior to conducting the study. Next, the principals of selected schools were contacted in writing to explain the purpose of the study and to solicit their support and approval. Upon approval, a covering letter and a passive consent form were sent to parents. The parents were also asked to complete a questionnaire and to return it to school before or on the day of the dental screening.

\section{Dental screening}

The Basic Screening Survey (BSS) was chosen as a quick and easy method for conducting oral screenings among children [23]. A 2-hour didactic training session utilizing a Microsoft PowerPoint presentation and discussion was conducted to explain the criteria of the BSS to 4 dental examiners. This was followed by a 3-hour clinical training session with a master examiner to train those examiners on the BSS criteria and methods. Twenty (20) children from similar age groups as the study participants were screened in the dental clinic of the school of dentistry by the master examiner and the 4 dental examiners. Standardization and calibration of the examiners with the master examiner was performed. The inter-examiner and intra-examiner reliability were $\geq 90 \%$ for detecting sealants and caries during this session prior to the start of the study.

On the actual visits, the dental screening was performed in a classroom with the student seated on a chair under 
artificial illumination with a headlamp. A visual and tactile examination with the aid of a disposable mouth mirror and toothpick was performed. Using the BSS criteria each tooth was assessed for caries experience, untreated dental caries and dental sealants. Caries experience was determined by the presence of an untreated cavity, a filling or a permanent molar tooth that was missing because it was extracted as a result of caries. Untreated caries was marked as present or absent in primary and permanent teeth (present $=1$, absent $=$ 0 ). Sealants were marked as present if at least 1 permanent molar was sealed $($ present $=1$, absent $=0)$.

Students' age, sex, grade and nationality were obtained during the dental screening sessions. In addition, the schools type, district and region were recorded.

The schools were revisited twice to complete the dental screenings for students who were absent the day of the first visit and to collect any returned questionnaires. Written reminder notes and text messages were sent to parents who did not return their questionnaires after each visit to the school. On completion of the dental screenings, parents who did not return their questionnaires or those who had missed key questions in their questionnaires were contacted by phone by the same dental examiners to complete the questionnaires.

\section{Parent questionnaire}

A self-administered questionnaire was sent home with the students to their parents. The questionnaire was mainly developed from the BSS manual questions. Other questions were added. The questionnaire was translated into Arabic and then back to English to make sure the meaning of the questions were not altered. Questions about selected socioeconomic status (SES) indicators (family income, educational attainment of both parents, type of home and receipt of government financial support), medical insurance, dental insurance, parents' perception of child's oral health, and child's utilization of dental services were included.

Monthly family income in Saudi riyals (SR) was categorized as: $<$ SR 3000, SR 3000-7000, SR 7001-10 000, SR 10 001-15 000, SR 15 001-20000 and > SR 20000 . Parental education was determined by taking the highest educational attainment achieved by each parent and was categorized as: illiterate, elementary school graduate, middle-school graduate, less than high school, high-school graduate, some college, college graduate, and higher than a college degree. Type of home was classified into low-cost housing (basic building materials, not reinforced with concrete); traditional apartment; and traditional house. Boys' and girls' schools were grouped into 4 regions according to their geographical location within the city: south, east, central and north for boys' schools and southeast, southwest, central, and north for the girls' schools. The schools' districts were classified into 5 SES levels (low, lower-middle, middle, upper-middle and high) based on the income of residents of these districts. The districts in the south area of Jeddah are the poorest, with about $70 \%$ of the government financial beneficiaries residing in the southern region of the city [personal communication, Saeed Al-Malki, Center for Statistics and Information, Jeddah, June 2010].

\section{Data entry and statistical analysis}

The data were entered into a Microsoft Access database from paper collection forms. After the data were checked for accuracy, they were imported into SAS, version 9.2 for statistical analysis. For analysis, family monthly income levels were consolidated into 3 levels: low ( $\leq$ 7000), middle (SR 7001-15 000) and high (> SR 15 000). Parental education attainment was consolidated into 3 categories: less than high-school attainment, high-school graduate and greater than high-school attainment. Finally, the SES levels of schools' districts were combined into 3 categories: low, medium and high. The prevalence of sealant use was calculated. The frequencies of children demographic factors, parents' SES indicators and school factors were calculated and their chi-squared statistics for sealant use were computed. Logistic regression models for dental sealant use and children's demographic and socioeconomic determinants were computed.

\section{Results}

Almost all the study students (1666/1668) were examined between March and June 2009 and $92 \%$ of parents of selected students completed and returned their questionnaires. The mean age of the sample was 12.1 [standard deviation (SD) 2.7] years: 9.1 (SD 0.7) years for 3rd grade students and 14.2 (SD 0.9) for 8th grade students. About $54 \%$ of the sample were 3 rd graders and $60 \%$ were males. The characteristics of the study group and the study schools are shown in Table 1.

The overall caries experience was 83.1\%: $91.6 \%$ in 3rd graders and $73.4 \%$ in 8 th graders. The proportion of untreated dental caries in primary and permanent teeth of all students were $63.0 \%$ and $56.7 \%$ respectively. Overall, 9.0\% had at least 1 sealed permanent molar (6.7\% in 3rd graders and $11.4 \%$ in 8 th graders) (Table 1). The students who had not received sealants were more likely to experience untreated caries than those who had received sealants. In 3rd graders the odds of caries in permanent teeth were 3 times higher among those who did not receive sealants compared with those who had received sealants $(\mathrm{OR}=0.32,95 \% \mathrm{CI}$ : $0.17-0.56)$. In 8 th graders these odds were 5 times higher among those who did not receive sealants as compared with those who did (OR 0.20; 95\% CI: 0.12-0.33) (Table 2). 


\begin{tabular}{|c|c|c|c|c|c|}
\hline Variable & No. of students & $\%$ & $\begin{array}{c}\text { Prevalence of sealant use } \\
\%\end{array}$ & $x^{2}$-value & $P$-value \\
\hline Student's age (years) & & & & 11.5 & $<0.001$ \\
\hline$<12$ & 885 & 53.1 & 6.7 & & \\
\hline$\geq 12$ & 783 & 46.9 & 11.4 & & \\
\hline Student's sex & & & & 11.6 & $<0.001$ \\
\hline Male & 998 & 59.9 & 10.8 & & \\
\hline Female & 669 & 40.1 & 6.0 & & \\
\hline Student's grade & & & & 12.0 & $<0.001$ \\
\hline 3rd grade & 891 & 53.4 & 6.6 & & \\
\hline 8 th grade & 777 & 46.6 & 11.5 & & \\
\hline Student's nationality & & & & 19.0 & $<0.001$ \\
\hline Saudi & 1153 & 69.4 & 11.0 & & \\
\hline Non-Saudi & 508 & 30.6 & 4.3 & & \\
\hline Student's receipt of school aid & & & & 4.2 & $<0.05$ \\
\hline Yes & 42 & 2.5 & 0.0 & & \\
\hline No & 1626 & 97.5 & 9.1 & & \\
\hline Mother's education & & & & 68.7 & $<0.001$ \\
\hline Illiterate & 171 & 10.9 & 2.9 & & \\
\hline Below high school & 572 & 36.7 & 4.0 & & \\
\hline High school & 397 & 25.5 & 6.6 & & \\
\hline Above high school & 419 & 26.9 & 17.5 & & \\
\hline Father's education & & & & 50.2 & $<0.001$ \\
\hline Illiterate & 67 & 4.3 & 1.5 & & \\
\hline Below high school & 502 & 32.5 & 3.4 & & \\
\hline High school & 409 & 26.5 & 6.6 & & \\
\hline Above high school & 568 & 36.7 & 14.5 & & \\
\hline Family income (SR) & & & & 89.6 & $<0.001$ \\
\hline$<7000$ & 940 & 62.7 & 3.7 & & \\
\hline $7001-15000$ & 397 & 26.5 & 10.8 & & \\
\hline$>15000$ & 163 & 10.9 & 24.5 & & \\
\hline Home type & & & & 73.7 & $<0.001$ \\
\hline Low-cost housing & 348 & 22.1 & 0.9 & & \\
\hline Apartment & 935 & 59.4 & 7.7 & & \\
\hline House & 292 & 18.5 & 19.6 & & \\
\hline $\begin{array}{l}\text { Family's receipt of government } \\
\text { support }\end{array}$ & & & & 0.22 & \\
\hline Yes & 63 & 4.1 & 6.4 & & \\
\hline No & 1446 & 94.9 & 8.0 & & \\
\hline School type & & & & 117.2 & $<0.001$ \\
\hline Public & 1378 & 82.7 & 5.4 & & \\
\hline Private & 289 & 17.3 & 25.4 & & \\
\hline Boys'school region & & & & 144.6 & \\
\hline South & 187 & 18.7 & 2.1 & & \\
\hline East & 463 & 46.4 & 4.5 & & \\
\hline Centre & 178 & 17.8 & 12.4 & & \\
\hline North & 170 & 17.0 & 35.9 & & \\
\hline
\end{tabular}




\begin{tabular}{|c|c|c|c|c|c|}
\hline Variable & No. of students & $\%$ & $\begin{array}{c}\text { Prevalence of sealant use } \\
\%\end{array}$ & $x^{2}$-value & $P$-value \\
\hline Girls'school region & & & & 21.5 & $<0.001$ \\
\hline Southwest & 261 & 39.0 & 2.3 & & \\
\hline Southeast & 130 & 19.4 & 1.4 & & \\
\hline Centre & 148 & 22.1 & 4.6 & & \\
\hline North & 130 & 19.4 & 11.2 & & \\
\hline School district SES & & & & 36.8 & $<0.001$ \\
\hline Low & 644 & 38.6 & 6.1 & & \\
\hline Medium & 446 & 26.7 & 21.6 & & \\
\hline High & 578 & 34.7 & 72.3 & & \\
\hline
\end{tabular}

Note: totals do not add up to 1666 because of missing data. $S E S=$ socioeconomic status; $S R=$ Saudi riyals.

The prevalence of sealant use varied significantly by student's sociodemographic factors, parent's educational attainment and by type, location and SES of the school (Table 1). The prevalence of dental sealants was significantly higher among male students, all students aged $12+$ years, 8 th graders and students attending private schools. The likelihood of having a child with at least 1 sealed permanent molar rose significantly with higher educational level of both mothers $\left(\chi^{2}\right.$ for trend $=$ 9.3, $P<0.05$ ) and fathers ( $\chi^{2}$ for trend $=6.8, P<0.05)$. Similarly, families with a high income were significantly more likely to have a child with sealed teeth compared with medium- and lowincome families.
Boys' schools located in the north area of Jeddah had the highest rate of students with dental sealants (35.9\%) $(P<0.05)$, followed by central Jeddah $(12.3 \%)$. East and south areas had the lowest rates (3.7\% and $2.1 \%$ respectively). Girls' schools located in the north and central regions of Jeddah had significantly more students with sealants ( $11.15 \%$ and $4.6 \%$ respectively) compared with the southwest and southeast of Jeddah ( $2.3 \%$ and $1.4 \%$ respectively).

Of the responding parents $22.2 \%$ reported that their child received dental care from public dental clinics, $71.7 \%$ from private dental clinics and 6.1\% from King Abdulaziz University School of Dentistry dental clinic. The prevalence of sealant use among these groups was $6.2 \%, 10.4 \%$ and $16.4 \%$ respectively $\left(\chi^{2}=7.21, P<0.05\right)$. In addition, nearly two-thirds $(65.1 \%)$ of responding parents reported that their child had been to the dentist before for different reasons. Among the children who had been to a dentist, only $13.3 \%$ received dental sealants $(P<0.001)$. The reasons reported by parents for taking their child to a dentist included: check-up or cleaning (32.2\%), toothache or cavities (63.1\%) and for treatment (4.7\%). Only $14.8 \%$ of children who had check-ups or cleaning, $6.1 \%$ of those who went for cavities or toothache and $14.0 \%$ of those who went for treatment had sealants placed on at least 1 permanent molar $(P<0.001)$. Only $4.8 \%$ of students who had caries in their primary teeth had

\begin{tabular}{|c|c|c|c|c|c|c|}
\hline \multirow[t]{3}{*}{ Untreated dental caries } & \multicolumn{4}{|c|}{ Sealant use } & \multirow[t]{3}{*}{$x^{2}$-value } & \multirow[t]{3}{*}{ OR $(95 \% \mathrm{CI})$} \\
\hline & \multicolumn{2}{|c|}{ No } & \multicolumn{2}{|c|}{ Yes } & & \\
\hline & No. & $\%$ & No. & $\%$ & & \\
\hline \multicolumn{7}{|c|}{ Primary teeth of 3rd graders $(n=880)$} \\
\hline Present & 680 & 82.7 & 35 & 60.3 & 17.8 & $0.32(0.18-0.56)$ \\
\hline Absent & 142 & 17.3 & 23 & 39.7 & & \\
\hline \multicolumn{7}{|c|}{ Permanent teeth of 3rd graders $(n=890)$} \\
\hline Present & 467 & 56.2 & 17 & 28.8 & 16.7 & $0.32(0.17-0.56)$ \\
\hline Absent & 364 & 43.8 & 42 & 71.2 & & \\
\hline \multicolumn{7}{|c|}{ Permanent teeth of 8th graders $(n=775)$} \\
\hline Present & 437 & 63.7 & 23 & 25.8 & 46.8 & $0.20(0.12-0.33)$ \\
\hline Absent & 249 & 36.3 & 66 & 74.2 & & \\
\hline
\end{tabular}

$O R=$ odds ratio $; C l=$ confidence interval. 


\begin{tabular}{|c|c|}
\hline Variable & OR (95\% Wald Cl) \\
\hline \multicolumn{2}{|l|}{ School type } \\
\hline Public & $0.41(0.26-0.66)$ \\
\hline Private & ref \\
\hline \multicolumn{2}{|l|}{ School grade } \\
\hline $3 r d$ & 0.74 (0.50-1.09) \\
\hline 8th & ref \\
\hline \multicolumn{2}{|l|}{ Sex } \\
\hline Male & $1.66(1.07-2.57)$ \\
\hline Female & ref \\
\hline \multicolumn{2}{|l|}{ Nationality } \\
\hline Saudi & $1.31(0.78-2.22)$ \\
\hline Non-Saudi & ref \\
\hline \multicolumn{2}{|l|}{ Mother's education } \\
\hline Below high school & $0.71(0.39-1.29)$ \\
\hline High school & ref \\
\hline Above high school & $1.62(0.97-2.72)$ \\
\hline High school & ref \\
\hline \multicolumn{2}{|l|}{ Father's education } \\
\hline Below high school & $0.51(0.27-0.98)$ \\
\hline High school & ref \\
\hline Above high school & $1.21(0.72-2.04)$ \\
\hline High school & ref \\
\hline
\end{tabular}

Wald $x^{2}=98.2, P<0.001$.

Ref $=$ Reference group; $O R=$ odds ratio; $C I=$ confidence interval.

sealed permanent molars compared with $11.9 \%$ of students who did not have caries in their primary teeth $\left(\chi^{2}=19.9, P\right.$ $<0.001$ ). The comparative figures for sealant use among students with and without caries in their permanent teeth were $4.3 \%$ and $14.9 \%$, respectively $\left(\chi^{2}=\right.$ $57.2, P<0.001)$.

A multivariate logistic regression model of sealant use is shown in $\mathrm{Ta}$ ble 3. The odds of having sealants on permanent molars were significantly higher in children attending private schools compared with students in public schools $(\mathrm{OR}=0.41,95 \% \mathrm{CI}$ : $0.26-0.66)$. In addition, fathers with less than high-school education were significantly more likely to have a child without sealants compared with fathers with high-school diplomas.

Pearson correlation coefficients were calculated for all socioeconomic of school district, family's monthly income, family's type of home, medical insurance and government financial support.

\section{Discussion}

This study assessed the prevalence of sealant use in the permanent molars of $3 \mathrm{rd}$ and 8 th grade schoolchildren and determined the socioeconomic determinants of sealant use in this group. Overall $9.0 \%$ of children had at least 1 sealed permanent molar and the use of sealants was much lower among children from lower socioeconomic backgrounds. Specifically, disparities in dental sealant use were noted in children of low-income families, children whose parents have low education attainment levels, children who live in low-cost housing and those who attend public schools located in low SES districts.

Unfortunately, data on sealant use from countries located in the same region are missing. Our result is similar to that reported for adolescents in Greece, where only $8 \%$ had at least 1 sealed permanent molar. The comparative prevalence of dental sealants on permanent teeth of US children and adolescents was $32 \%$ in 1999-2002 [21]. In addition, the current percentage (9\%) of sealed permanent teeth in Saudi children was even less than the percentage (22\%) reported for US children and adolescents living below $100 \%$ federal poverty level [21].

Despite the safety and effectiveness of sealants, they are still underutilized in the prevention of dental caries in Saudi children [24]. Our findings indicate that more than $80 \%$ of $3 \mathrm{rd}$ and 8th grade children had dental caries and about $60 \%$ suffered from untreated dental decay. These findings provide evidence for the pressing need for comprehensive public oral health prevention programmes for children. Oral health education on its own may not 


\begin{tabular}{lc}
\hline Table 4 Stepwise logistic model of the association between students' \\
socioeconomic characteristics and dental sealant use \\
\hline Variable & OR $(95 \%$ Wald CI $)$ \\
School SES district (high versus medium $\left.{ }^{\mathrm{a}}\right)$ & $1.65(1.01-2.70)$ \\
School SES district (low versus medium $)$ & $0.25(0.10-0.60)$ \\
Family income (high versus middle $\left.^{\mathrm{a}}\right)$ & $1.51(0.87-2.61)$ \\
Family income (low versus middle $\left.^{\mathrm{a}}\right)$ & $0.57(0.35-0.99)$ \\
Housing (low-cost versus house $\left.^{\mathrm{a}}\right)$ & $0.16(0.03-0.74)$ \\
Housing (apartment versus house $\left.^{\mathrm{a}}\right)$ & $0.78(0.47-1.29)$ \\
Medical insurance (yes versus no $\left.^{\mathrm{a}}\right)$ & $1.61(1.04-2.50)$ \\
Government support (yes versus no $\left.^{\mathrm{a}}\right)$ & $0.17(0.05-0.61)$ \\
\hline
\end{tabular}

${ }^{a}$ Reference group.

$S E S=$ socioeconomic status; $O R=$ odds ratio; $C I=$ confidence interval.

be enough to bring these alarming rates down. A school preventive oral health programme can incorporate several elements, such as oral health education, dental screenings, referral for dental treatment, fluoride mouthrinsing and sealant applications [25]. Immediate measures must be taken to reach out to these children, particularly those of lower SES. Targeting high-risk schools to reach high-risk children is a practical and effective approach for increasing sealant prevalence [26]. Collaboration among different government agencies and providers is critical for implementing and sustaining such programmes.

Our study also showed that sealants were underutilized by dentists. There may be many missed opportunities for placing dental sealants in children who attend dental visits, especially among those who attend for prevention rather than for emergency treatment. Farsi reported that onethird of private dentists in Jeddah did not use any sealants in their practice [24]. Reasons for underutilization of dental sealants reported by these dentists included patients' low valuation of sealants, patients' unwillingness to pay for sealants, short survival of sealants in the mouth, not treating enough children and reduced costeffectiveness compared with amalgam restorations [24]. Therefore, to increase sealant utilization at the public and individual levels, dentists need to be educated and motivated to use dental sealants on children's teeth. Sustained efforts, however, are needed to change their attitudes towards use of dental sealants [24]. Furthermore, community education on the values of dental sealants in the be part of any oral health promotion programme.

The significant socioeconomic determinants of sealant use were SES of school district, family's monthly income, family's type of home, medical insurance and government financial support. These findings can help us to develop and implement costeffective public oral health prevention programmes targeted at high-risk children. School-based or school-linked programmes that target low-income schools are one way of implementing such programmes [27]. Federally subsidized school lunch programmes in the US provide a successful means for identifying children from low SES communities in high need for both dental prevention and intervention $[28,29]$. Such children have consistently higher levels of oral disease and lower prevalence of sealant use compared with children from higher SES communities [28,29]. Similarly, ownership of a medical card by a child prevention of dental caries should in the UK is used to identify high-risk children who benefit most from these interventions [30].

The strengths of this study include its high response rate (92\%) and the use of stratified and proportional random sampling, which rendered our findings representative of schoolchildren in Jeddah, Saudi Arabia. The fact that this was a cross-sectional study limited the ability to assess a cause-effect relationship between low sealant use and SES determinants. In addition, the temporal relationship between sealant use and caries was difficult to assess. Therefore, it is possible that these children received dental sealants because they had caries.

In conclusion, the prevalence of sealant use on permanent teeth of children and adolescents in Jeddah is low, and disparities in sealant use existed among children from different SES groups. Based on the findings of this study, schools located in lower SES districts in Jeddah with high numbers of children living in low-cost housing can be used to target effectively children in need of oral health intervention programmes. Implementing and sustaining these programmes could increase the prevalence of dental sealant use and eventually help reduce disparities in dental caries prevalence among children.

\section{Acknowledgements}

This study was funded by a grant from King Abdulaziz University Deanship of Scientific Research (Grant No.: 429/014-9). Many thanks are due to: the dental interns who assisted with the administration of the questionnaire for their hard work and commitment; the principals, teachers, and staff of all the participating schools for their support and cooperation; and the students for cooperating with the survey. 


\section{References}

1. Oral health in America: a report of the Surgeon General. Rockville, Maryland, National Institutes of Health, National Institute of Dental and Craniofacial Research, 2000.

2. Petersen PE. Changing oral health profiles of children in Central and Eastern Europe. Challenges for the 21st century. IC Digest, 2003, 2:12-13.

3. Al-Sekait MA, Al-Nasser AN. Dental caries prevalence in primary Saudi school children in Riyadh district. Saudi Medical Journal, 1988, 9:606-609.

4. Al-Shammary A, Guile E, El-Buckly M. Prevalence of caries in primary school children in Saudi Arabia. Community Dentistry and Oral Epidemiology, 1990, 6:320-321.

5. Al-Khateeb TL, Al-Marsafi AL, O'Mullane DM. Caries prevalence and treatment need amongst children in an Arabian community. Community Dentistry and Oral Epidemiology, 1991, 19:277-280.

6. Alamoudi N, Salako NO, Massoud I. Caries experience of children aged 6-9 years in Jeddah, Saudi Arabia. International Journal of Paediatric Dentistry, 1996, 6:101-105.

7. Gandeh MBS, Milaat WA. Dental caries among schoolchildren: report of a health education campaign in Jeddah, Saudi Arabia. Eastern Mediterranean Health Journal, 2000, 6:396-401.

8. Al- Khateeb TR et al. Dental caries in children residing in Saudi Arabia with differing levels of natural fluoride in the drinking water. Community Dental Health, 1990, 7:165-171.

9. Stewart BL et al. Caries experience in grades 1 and 6 children attending elementary schools at King Abdulaziz military city, Tabuk, Saudi Arabia. Saudi Dental Journal, 2000, 12:140-148.

10. Aldosari AM et al. Caries prevalence and its relation to water fluoridation levels among schoolchildren in Central province of Saudi Arabia. International Dental Journal, 2004, 54:424428.

11. Preventing dental caries: school-based or-linked sealant delivery programs. The Guide to Community Preventive Services [online] (http://www.thecommunityguide.org/oral/schoolsealants.html, accessed 10 September 2012).

12. Burt BA. Trends in caries prevalence in North American children. International Dental Journal, 1994, 44(Suppl. 1):403-413.

13. Gilpin JL. Pit and fissure sealants: a review of the literature. Journal of Dental Hygiene, 1997, 71:150-156.

14. Oral health in America: a report of the Surgeon General. Executive summary. Rockville, Maryland, National Institute of Health, National Institute of Dental and Craniofacial Research, 2000.

15. Ahovuo-Saloranta A et al. Pit and fissure sealants for preventing dental decay in the permanent teeth of children and adolescents. Cochrane Database of Systematic Reviews, 2008, Issue 4:CD001830.
16. Wellbury R, Raadal M, Lygidakis NA. EAPD guidelines for the use of pit and fissure sealants. European Journal of Paediatric Dentistry, 2004, 5:179-184.

17. Kallestal $\mathrm{C}$ et al. Caries-preventive methods used for children and adolescents in Denmark, Iceland, Norway and Sweden. Community Dentistry and Oral Epidemiology, 1999, 27:144-151.

18. Ekstrand KR, Martignon S, Christiansen ME. Frequency and distribution patterns of sealants among 15-year-olds in Denmark in 2003. Community Dental Health, 2007, 24:26-30.

19. Pit and fissure sealants: evidence-based guidance on the use of sealants for the prevention and management of pit and fissure caries. Cork, Ireland, Irish Oral Health Services Guideline Initiative, 2010.

20. Oulis CJ et al. Prevalence of sealants in relation to dental caries on the permanent molars of 12 and 15 -year-old Greek adolescents. A national pathfinder survey. BMC Public Health, 2011, 14(11):100.

21. Beltran-Aguilar ED et al. Surveillance for dental caries, dental sealants, tooth retention, edentulism, and enamel fluorosis-United States, 1988-1994 and 1999-2002. Morbidity and Mortality Weekly Report, 2005, 54:1-44.

22. Healthy people 2010. Focus area 21: oral health. Washington DC, US Government Printing Office, 2000.

23. Basic screening surveys: An approach to monitoring community oral health. Sparks, Nevada, Association of State and Territorial Dental Directors, 1999.

24. Farsi N. The effect of education upon dentists' knowledge and attitude toward fissure sealants. Odonto-stomatology Tropicale, 1999, 86:27-32.

25. Best practice approach reports: school-based dental sealant programs. Sparks, Nevada, Association of State and Territorial Dental Directors, 2003.

26. Siegal MD, Detty AM. Do school-based dental sealant programs reach higher risk children. Journal of Public Health Dentistry, 2010, 70(3):181-187.

27. Truman $\mathrm{BI}$ et al. Reviews of evidence on interventions to prevent dental caries, oral and pharyngeal cancers, and sportrelated craniofacial injuries. American Journal of Preventive Medicine, 2002, 23(1S):21-54

28. Gillcrist JA, Brumley DE, Blackford JU. Community socioeconomic status and children's dental health. Journal of the American Dental Association, 2001, 132:216-222.

29. Ripa LW, Leske GS, Kaufman HW. Caries prevalence, treatment level, and sealant use related to school lunch program participation. Journal of Public Health Dentistry, 1991, 51:78-81.

30. Sagheri D, McLoughlin J, Clarkson J. The prevalence of dental caries and fissure sealants in 12-year old children by disadvantaged status in Dublin (Ireland). Community Dental Health, 2009, 26(1):32-37. 